\title{
ANALISA PENGARUH PENERAPAN BUDAYA $5 S$ TERHADAP PRODUKTIVITAS KARYAWAN DI PT SAMSUNG ELECTRONICS INDONESIA, BEKASI
}

\author{
Albertus Djaka Yudhanto ${ }^{1}$, Purwanto ${ }^{2}$ \\ ${ }^{1}$ Jurusan Manajemen, Fakultas Bisnis, Universitas Presiden \\ Email: albertusyudhanto08@gmail.com \\ ${ }^{2}$ Jurusan Manajemen, Fakultas Bisnis, Universitas Presiden \\ Email: Purwanto@president.ac.id
}

\begin{abstract}
ABSTRAK
Strategi memenangkan persaingan telah memicu penerapan konsep baru di perusahaan manufaktur khususnya industri elektronik. Tujuan penelitian ini adalah menginvestigasi dampak penerapan budaya $5 S$ sebagai upaya meningkatkan produktivitas karyawan PT Samsung Electronics Indonesia dengan menggunakan pendekatan kuantitatif. Sumber primer yang dikumpulkan melalui bantuan instrumen kuesioner dibagikan ke responden yang telah terlibat langsung. Jumlah sampel sebanyak 155 karyawan di bagian Manufacturing Engineering Departement. Pengolahan dan analisis diawali uji validitas dan reliabilitas. Deskripsi data direpresentasikan dengan angka minimum, maksimum, rata-rata dan standar deviasi. Pemenuhan tahapan uji asumsi klasik yang berupa normalitas, heterokedastisitas, multikolinearitas dan autokorelasi harus dilakukan sebelum regresi linier berganda. Hasil uji parsial dan simultan memperlihatkan bahwa seiri, seiton, seiso, seiketsu dan shitsuke memiliki kontribusi positif signifikan terhadap produktivitas karyawan. Proporsi semua variabel bebas terhadap variabel terikat yang digambarkan oleh nilai koefisien determinasi (adjusted $R$ Square) sebesar 0,460 atau 46\%, sedangkan sisanya (54\%) ditentukan faktor lain. Peranan shitsuke paling dominan selama proses pengamatan, artinya kerajinan dan pembiasaan untuk bertindak terhadap apa yang diinginkan harus ditempuh meskipun sulit.
\end{abstract}

Kata Kunci: Seiri, Seiton, Seiso, Seiketsu, Shitsuke, Produktivitas Karyawan

\section{ABSTRACT}

The strategy to win the competition has triggered the application of new concepts in manufacturing companies, especially the electronics industry. The aims of this research is to investigate the impact of implementing $5 S$ culture as an effort to increase the productivity of PT Samsung Electronics Indonesia by using a quantitative approach. Primary sources collected through the help of questionnaire instruments were distributed to respondents who had been directly involved. The total sample of 155 employees in the Manufacturing Engineering Department. Processing and analysis begins with a validity and reliability test. The description of the data is represented by minimum, maximum, average and standard deviation. Fulfillment of the classical assumption test stages in the form of normality, heterokedasticity, multicollinearity and autocorrelation must be performed before multiple linear regression. Partial and simultaneous test results show that seiri, seiton, seiso, seiketsu and shitsuke have a significant positive contribution to employee productivity. The proportion of all independent variables to the dependent variable described by the coefficient of determination (adjusted $R$ Square) of 0.460 or $46 \%$, while the rest $(54 \%)$ is determined by other factors. Shitsuke's role is most dominant during the observation process, meaning that the craft and habituation to act on what is desired must be pursued even though it is difficult.

Keywords: Seiri, Seiton, Seiso, Seiketsu, Shitsuke, Employee Productivity

\section{PENDAHULUAN}

\section{Latar Belakang}

Pesatnya pertumbuhan industri di Indonesia baik di bidang manufaktur maupun jasa mulai skala kecil, menengah dan besar menuntut kualitas yang dihasilkan (Nina, H, 2013). Fenomena ini juga berimbas di bidang usaha elektronik yang pasarnya di wilayah domestik maupun internasional. Persaingan yang sangat ketat agar dapat mempertahan hidupnya menjadi sebuah keharusan. Keunggulan dan ketangguhan sumber daya manusia melalui berbagai pelatihan yang berkualitas menjadi kunci terwujudnya kualitas produk yang dihasilkan sesuai keinginan 
konsumen. Pelanggan dan pembeli baru akan merasa puas jika produk yang dibeli sesuai keinginan atau terpenuhi kebutuhannya. Aktivitas proses produksi menjadi kunci meraih tujuan tersebut. Dalam sebuah perusahaan sangat penting untuk memberikan kualitas dan produktivitas yang semata-mata bergantung pada cacat produk, kecelakaan kerja, waktu jeda pada saat kinerja operasional, kondisi kerja, kebersihan dan lain-lain (Pasale, 2013). Perusahaan yang mampu memperhatikan kualitas secara serius akan berdampak menjadi efektif melalui pembelajaran nilai-nilai budaya kerja yang terkandung dalam $5 S$, yakni ringkas (seiri), rapi (seiton), resik (seiso), rawat (seiketsu) dan rajin (shitsuke) (Osada, 2004).

Banyak perusahaan di Indonesia menerapkan konsep baru untuk memenangkan persaingan dengan konsep just in time (JIT), total productive maintenance (TPM), total quality management (TQM), ISO 9000, quality control circle (QCC). Sebelum melakukan itu semuanya maka seharusnya diedukasikan lebih awal sebagai kultur kerja dengan pendalaman $5 S$ yakni seiri, seiton, seiso, seiketsu dan shitsuke. Dengan lingkungan kerja yang nyaman akan membuat seseorang lebih giat bekerja dan kinerjanya semakin meningkat. PT Samsung Electronics Indonesia (PT SEIN) adalah perusahaan yang bergerak dalam bidang elektronik terkemuka. Hasil produksi perusahaan ini sebagian besar dipasarkan secara ekspor dan domestik. Proses produksi perusaahaan ini dimulai dari persiapan material (kitting inbound), proses perakitan, proses inspeksi, pengepakan dan penyimpanan barang jadi (finish good) dimana set yang sudah disusun siap untuk dikirim ke luar negeri ataupun dipasarkan untuk lokal market. Perusahaan ini memang sudah menerapkan konsep Toyota Production System (TPS), Samsung Production System (SPS) dan penerapkan $5 S$, namun saat ini belum maksimal dan masih terus dalam tahap perbaikan. Masih sering terjadi terjadi berbagai permasalahan dibeberapa area produksi dan bagian lain yang perlu disempurnakan. Permasalahan ini tentu akan sangat menganggu proses produksi, penurunan kualitas produk dan kinerja karyawan. Salah satu yang menjadi perhatian manajemen PT SEIN dalam penyusunan kebijakan yang menyangkut kinerja karyawan adalah meningkatkan pelatihan, metode kerja dan budaya kerja yang membuat para karyawan menikmati pekerjaan yang sudah dibebankan kepada mereka. Kemampuan tenaga kerja yang handal akan dibangun oleh sistem budaya yang memungkinkan orang-orang di dalamnya dapat memenuhi dan memberikan kepuasan karyawan maupun manajemen organisasi.

Riset ini melibatkan penulis yang berposisi sebagai karyawan bagian Manufacturing Engineering yang mana dibagian ini merupakan tim inti perusahaan dalam melakukan pengembangan produk baru, perawatan, perbaikan mesin dan peralatan (equipment) produksi, juga sebagai tim pendukung terhadap bagian produksi. Penulis akan melakukan penelitian dibagian ini, apakah budaya kerja $5 S$ berpengaruh terhadap produktivitas karyawan. sikap kerja $5 \mathrm{~S}$ merupakan faktor penentu terciptanya efektifitas kerja di departemen produksi, tetapi lebih kepada faktor lain (Kartika, 2011). Mengacu gambar di bawah bahwa jumlah kerusakan produk (defect product) setiap bulannya di tahun 2019 masih banyak dan puncaknya di bulan April - Mei, kondisi ini menunjukkan bahwa kualitas produk semakin menurun yang berakibat tingkat produksi juga semakin turun. Realitas yang ada dapat dikaitkan dengan adanya ketidaksesuaian material, proses produksi, analisa kapasitas produksi, dukungan dari bagian terkait yang dianggap kurang, penempatan material yang tidak sesuai, jadwal kedatangan material yang tidak sesuai dengan jadwal, area kerja yang tidak nyaman, kotor dan kurang rapih, maka dapat menyebabkan meningkatnya kerusakan produk dan kualitas produk. 


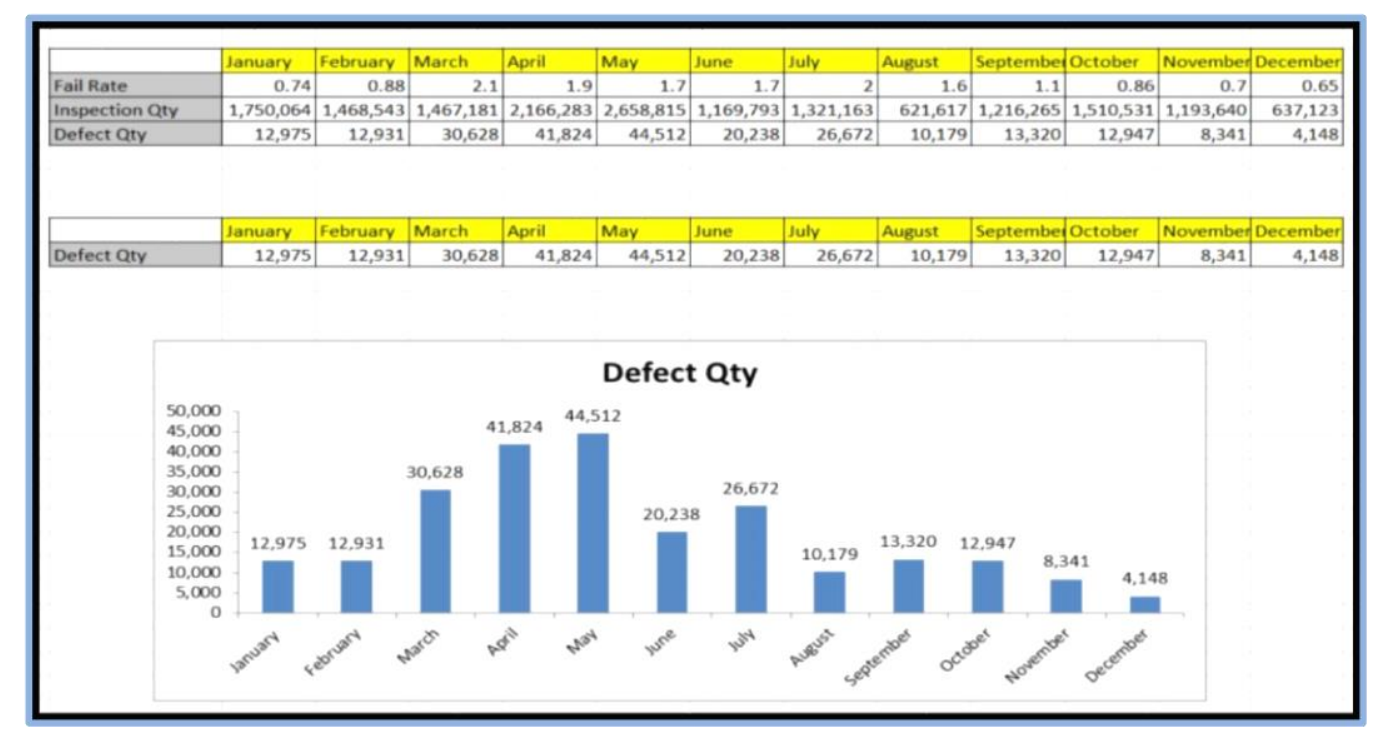

Gambar 1. Data Bulanan Kerusakan Kualitas

Sumber: Data Quality in Process TV AV Production, 2019

Halim (2006) dalam tulisannya mengatakan bahwa seiri sebagai tindakan menyusun yang didalamnya termasuk pemilahan alat, material dan seterusnya di lapangan kerja dan menjamin benda-benda yang dibutuhkan dapat dijangkau dari tempat menyimpan agar efisiensi serta mempertimbangkan jumlah penggunaan. Seiton diartikan sebagai penyimpanan benda agar di area pekerjaan secara tepat atau peletakannya sesuai agar jika keadaan mendesak dapat segera digunakan. Langkah ini untuk mengeliminasi dalam proses mencari (Waluyo, 2011).

Menurut Henriadi (2012), seiso dimaksudkan sebagai pembersihan benda agar kelihatan bersih. Pengurangan secara besar sebuah panjang lintasan material handling, yaitu $45 \mathrm{~m}$ atau sekitar 19,2\% lebih pendek dari layout awal. Menggunakan implementasi budaya 5S tersebut maka menghasilkan lingkungan kerja di pabrik secara fisik lebih indah dan rapi sehingga karyawan merasa nyaman. Hasil penelitian Tanson (2011) menyebutkan bahwa penerapan seiri dan safety sudah cukup baik, yaitu nilai di atas 3,0, setelah implementasi yang dilakukan memperlihatkan pada pilar set in order dan shine bertambah ke arah 2,9 sedangkan standardize menjadi 3,0.

\section{Rumusan Masalah}

Mengacu pemaparan fenomena permasalahan maka keharusan diadakan investigasi lebih lanjut agar dapat diberikan alternatif solusinya. Berbagai ketidaksesuaian yang timbul selama ini di antaranya:

1. Belum meratanya edukasi dan pengertian kultur kerja yang seharusnya bagi para pekerja Indonesia yang mengakibatkan terbatasnya daya serap masyarakat di dunia industri.

2. Terdapat beberapa prosedur dan instruksi kerja yang tidak dihiraukan oleh para karyawan, terutama menyangkut perilaku, sikap, tindakan dan optimalisasi waktu, ruang kerja, kedisiplinan, kerapihan, keakuratan, target, kualitas hasil kerja yang menjadi penghalang saat bekerja maupun lingkungan kerja.

3. Perilaku sejumlah karyawan saat datang ke kantor atau perusahaan yang sering terlambat dengan berbagai alasan sehingga mempengaruhi pencapaian target yang sudah ditetapkan oleh pimpinan.

4. Kebiasaan pekerja yang mengerjakan tugas dengan kondisi berantakan dan jarang mengembalikan berbagai peralatan yang telah digunakan ke tempat semula akan menghambat kelancaran dalam proses produksi secara keseluruhan. 
5. Belum terlihat adanya kondisi informasi yang ergonomis. Penataan yang tidak rapi pada proses kerja dan penyimpanan peralatan kerja yang tidak pada tempatnya.

Identifikasi yang sudah dibuat dimaksudkan dapat memberikan masukan demi perbaikan dan kemajuan perusahaan PT SEIN. Adapun tujuan penelitian sebagai berikut:

1. Mengetahui efektivitas penyadaran seiri, seiton, seiso, seiketsu dan shitsuke

2. Merancang seiri di PT SEIN untuk mengeliminasi yang tidak diperlukan, melakukan stratifikasi manajemen.

3. Merancang seiton di PT SEIN dalam menetapkan tempat penyimpanan barang-barang di area kerja, menambah optimalisasi hasil produksi dengan meminimalkan waktu terbuang untuk pencarian peralatan.

4. Merancang seiso di PT SEIN untuk mengatasi semua permasalahan kebersihan dan menemukan penyebab permasalahan setiap bagian.

5. Merancang seiketsu di PT SEIN untuk pemantapan yang dilakukan secara periodik dan berkesinambungan di saat menjaga proses pemisahan, menata ulang dan cleaning area.

6. Merancang shitsuke di PT SEIN untuk membiasakan kegiatan dalam memenuhi prosedur kerja, berinteraksi dan saling memberi kritik maupun masukan pihak lain secara terusmenerus.

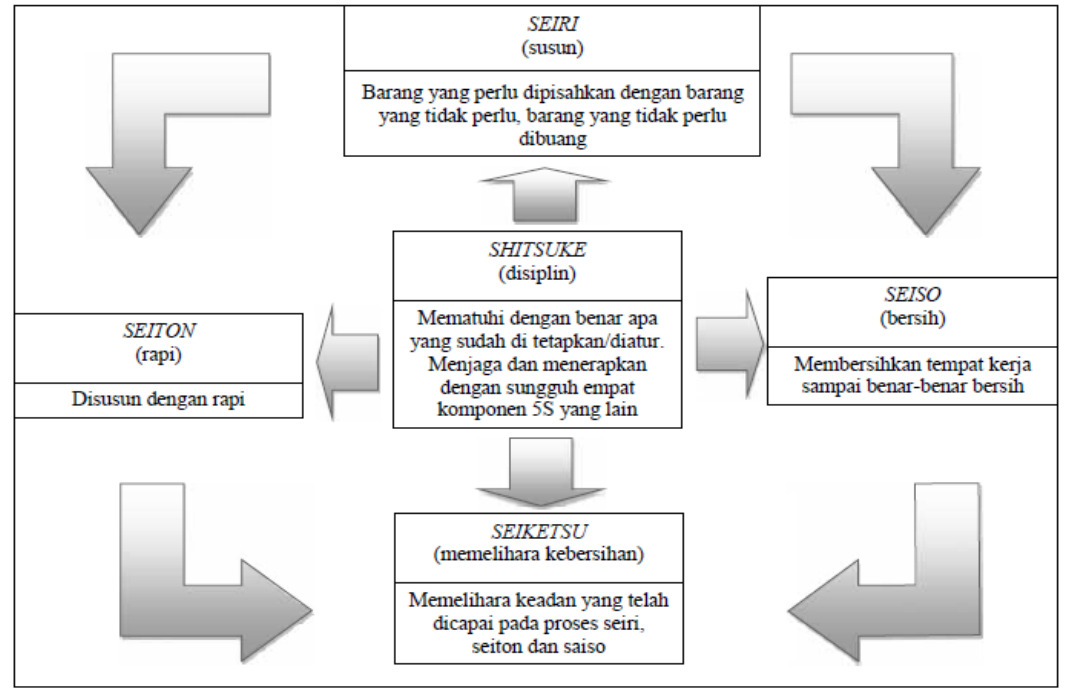

Gambar 2. Siklus $5 S$

Sumber: Widodo, 2009

\section{Hipotesis}

Merupakan dugaan sementara yang masih harus dilakukan pengujian untuk memperoleh kebenarannya. Adapun hipotesisnya dapat dirumuskan sebagai berikut:

Hipotesis 1 : Penerapan $5 S$ secara simultan berpengaruh terhadap produktivitas karyawan.

Hipotesis 2 : Seiri berpengaruh terhadap produktivitas karyawan.

Hipotesis 3 : Seiton berpengaruh terhadap produktivitas karyawan.

Hipotesis 4 : Seiso berpengaruh terhadap produktivitas karyawan.

Hipotesis 5 : Seiketshu berpengaruh terhadap produktivitas karyawan.

Hipotesis 6 : Shitsuke berpengaruh terhadap produktivitas karyawan. 


\section{METODE PENELITIAN}

Penelitian ini memakai metode kuantitatif yang menuju ke arah pengukuran fenomena sosial secara obyektif dengan cara-cara matematis, teori-teori serta hipotesis. Creswell (2014) menyatakan bahwa penelitian kuantitatif merupakan sebuah pendekatan untuk menguji teoriteori tentang hubungan antar variabel, banyaknya data dapat dianalisis menggunakan prosedur statistik. Pengambilan sampel dilakukan secara purposive sampling, yaitu salah satu teknik non random sampling dengan cara menetapkan ciri-ciri khusus yang sesuai tujuannya. Jumlah sampel sebanyak 155 orang di bagian Manufacturing Engineering yang pernah terlibat langsung dalam penerapan dan pelaksanaan kegiatan $5 S$. Departemen ini dibagi dalam 3 (tiga) divisi, yaitu Hand Held Phone Division ( HHPDivision ), TV/AV Division dan Set Top Box Division ( STB Division ). Instrumen yang digunakan untuk pengambilan data primer berbentuk kuesioner dan dibagikan ke seluruh karyawan yang sebelumnya telah dilakukan uji validitas dan reliabilitas terhadap 30 orang. Pemakaian skala Likert dalam kuesioner dikerjakan oleh orang-orang yang telah ditentukan sebagai obyek riset ditetapkan (Sugiyono, 2015). Valid dan konsistensi setiap pertanyaan dalam kuesioner sangat penting untuk mengukur apakah instrumen tersebut akurat sebagai pengumpul data. Apabila ditemukan hasil yang bias maka dapat dilakukan modifikasi atau menghilangkan sebagian pertanyaan yang ada. Kehandalan (reliability) merupakan ukuran untuk menghasilkan data yang konsisten apabila dilakukan beberapa kali terhadap karakter atau sifat tertentu.

Analisis deskripsi berupa terendah, tertinggi, mean dan simpangan baku. Sebelum dilakukan estimasi regresi, semua data harus memenuhi uji asumsi klasik. Uji normalitas dapat dilihat dari data apakah berbentuk distribusi normal atau tidak. Heteroskedastisitas untuk menentukan apakah suatu model terbebas dari masalah heteroskedastisitas dengan melihat scatter plot residual memiliki pola tertentu atau tidak. Uji multikolinearitas bertujuan untuk menguji apakah pada model regresi ditemukan adanya korelasi antara variabel independen. Cara mendeteksinya melalui nilai toleransi dan variance inflation factor (VIF). Tidak terjadi multikolinearitas jika toleransinya lebih besar dari 0,10 dan terdapat multikolinearitas apabila toleransinya di bawah atau sama dengan 0,10 atau VIF $>0,10$ maka tidak terjadi multikolinearitas dan nilai VIF $<0,10$ terjadi multikolinearitas.

Selanjutnya model estimasi persamaannya dapat dituliskan sebagai berikut:

Keterangan:

$$
\mathrm{Y}=\alpha+\beta_{1} \mathrm{X}_{1}+\beta_{2} \mathrm{X}_{2}+\beta_{3} \mathrm{X}_{3}+\beta_{4} \mathrm{X}_{4}+\beta_{5} \mathrm{X}_{5}+\mathrm{e}
$$

$\beta_{1}-\beta_{5}=$ Koefisien Regresi $X_{1}-X_{5}$

$\mathrm{Y}=$ Produktivitas Karyawan

$\mathrm{E} \quad=$ error

$\alpha \quad=$ Konstanta 


\section{HASIL DAN PEMBAHASAN}

Uji Normalitas

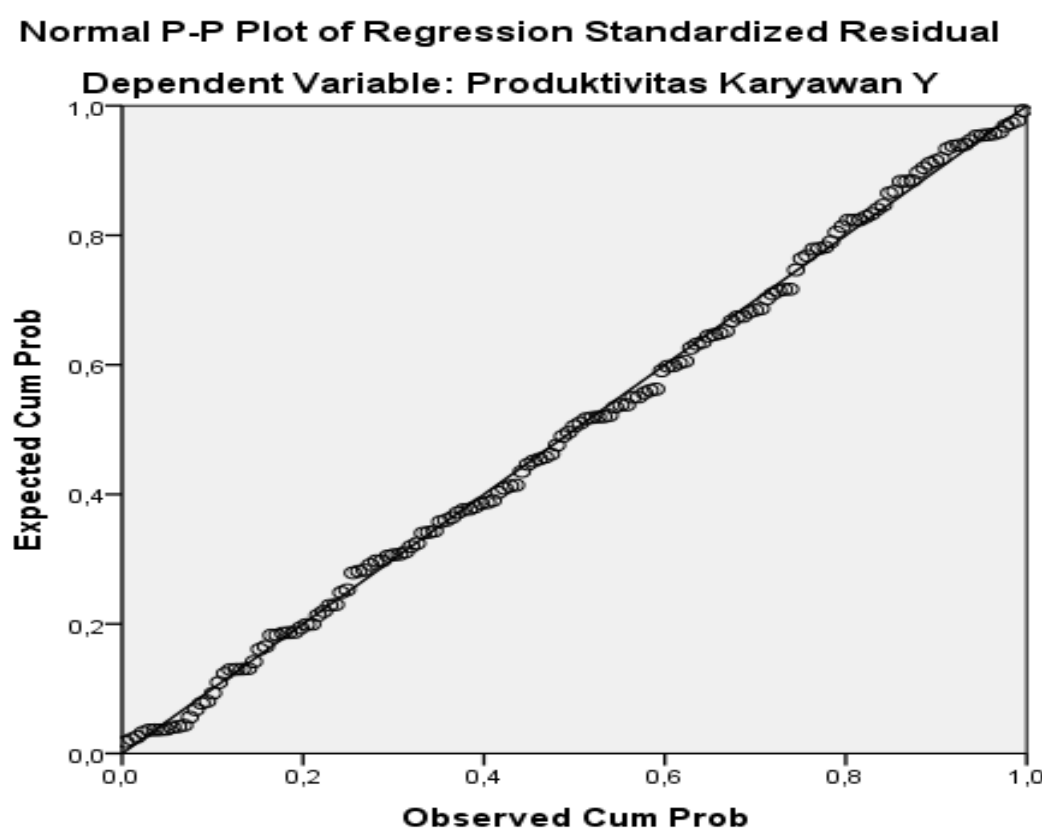

Gambar 3. Hasil Pengujian Normalitas dengan Normal P-P Plot

Sumber : Keluaran program SPSS 21 for Windows

Gambar 3 memperlihatkan titik-titk terdistribusi di wilayah atas atau bawah garis diagonal dan mengacu model regresi, artinya dapat diartikan dataterpenuhi sehingga fase uji normalitas sesuai standar.

\section{Uji Heteroskedastisitas}

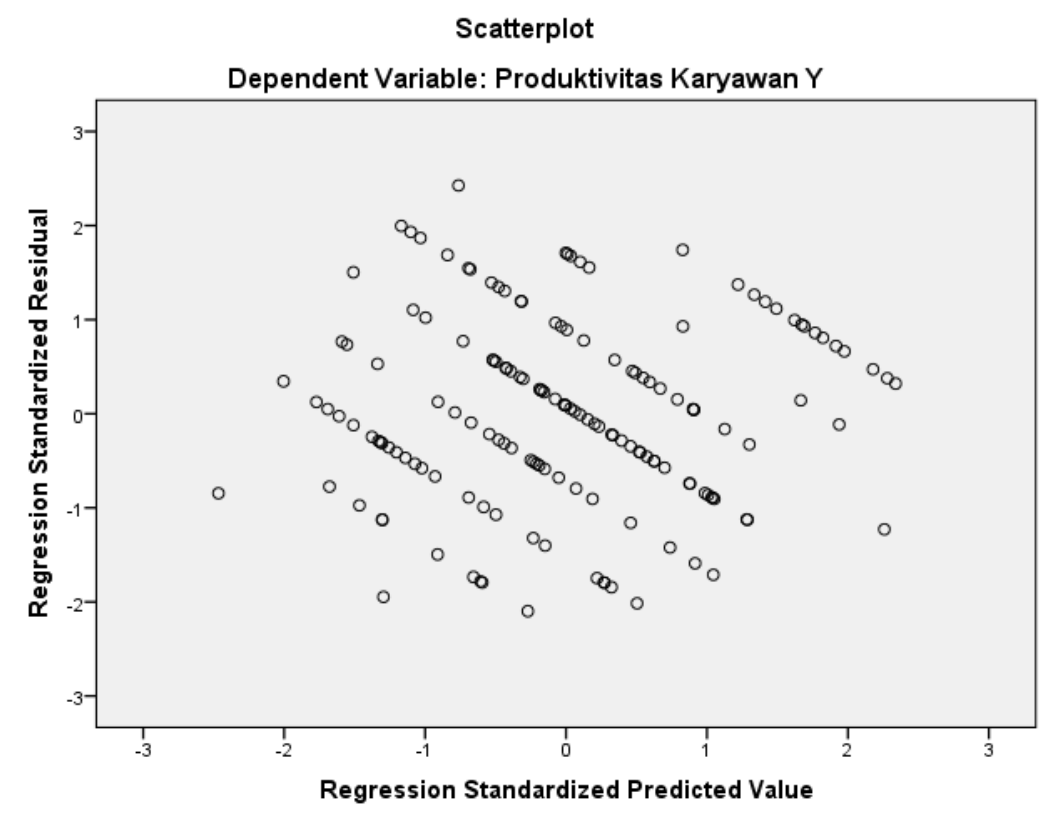

Gambar 4. Hasil Pengujian Heteroskedastisitas Scatter Plot Sumber : Output Program SPSS 21 for Windows

Hasil di atas mengilustrasikan adanya penyebaran titik-titik di wilayah garis-garis diagonal dan mengikuti model regresi. Bentuk distribusi normal dari hasil olahan data menandakan terpenuhinya uji normalitas. 


\section{Analisa Regresi Linier Berganda}

Tabel 1. Hasil Pengujian Regresi Linier Berganda

Sumber : Output program SPSS 21 for Windows

\begin{tabular}{|c|c|c|c|c|c|c|}
\hline \multicolumn{7}{|c|}{ Coefficients $^{a}$} \\
\hline \multirow{2}{*}{\multicolumn{2}{|c|}{ Model }} & \multicolumn{2}{|c|}{ Unstandardized Coefficients } & \multirow{2}{*}{$\begin{array}{c}\begin{array}{c}\text { Standardized } \\
\text { Coefficients }\end{array} \\
\text { Beta } \\
\end{array}$} & \multirow[b]{2}{*}{$t$} & \multirow[b]{2}{*}{ Sig. } \\
\hline & & $\mathrm{B}$ & Std. Error & & & \\
\hline \multirow[t]{6}{*}{1} & (Constant) & $-3,934$ & 2,948 & & $-1,334$ &, 184 \\
\hline & Seiri $(\times 1)$ &, 118 & 059 & .120 & 2,004 &, 047 \\
\hline & Seiton $(\times 2)$ & 152 &, 068 &, 136 & 2,252 &, 026 \\
\hline & Seiso $(\times 3)$ &, 211 & 095 &, 135 & 2,229 &, 027 \\
\hline & Seiketsu $(\times 4)$ &, 316 &, 068 & 342 & 4,643 &, 000 \\
\hline & Shitsuke (X5) & ,371 &, 072 &, 378 & 5,170 &, 000 \\
\hline
\end{tabular}

a. Dependent Variable: Produktivitas Karyawan $(\mathrm{r})$

Model estimasi regresi linier berganda dapat ditunjukkan sebagai berikut:

$$
Y=0,120 X_{1}+0,136 X_{2}+0,135 X_{3}+0,342 X_{4}+0,378 X_{5}
$$

Selanjutnya persamaan tersebut di atas dapat dijelaskan bahwa:

a. Koefisien seiri memberikan nilai sebesar 0,120 yang berarti bahwa jika seiri mengalami peningkatan satu satuan maka produktivitas karyawan akan meningkat sebesar 0,120 dengan anggapan variabel lain tidak berubah.

b. Nilai sebesar 0,136 pada seiton menggambarkan makna bahwa jika seiton terjadi kenaikan satu satuan maka produktivitas karyawan akan mengalami peningkatan sebesar 0,136 dengan pengertian variabel lain konstan.

c. Angka seiso menunjukkan nilai sebesar 0,135 yang berarti bahwa jika seiso terjadi kenaikan satu satuan maka produktivitas karyawan akan bertambah sebesar 0,135 tetapi variabel lain tidak berubah

d. Seiketsu menghasilkan angka sebesar 0,342, artinya jika seketsu bertambah satu satuan maka produktivitas karyawan akan meningkat sebesar 0,342 dengan catatan tidak ada perubahan variabel lain.

e. Koefisien shitsuke memberikan nilai sebesar 0,378 yang berarti bahwa jika shitsuke mengalami peningkatan satu satuan maka produktivitas karyawan akan terjadi penambahan angka sebesar 0,378 dengan anggapan tidak ada pergeseran variabel lain.

\section{Pengujian Uji Hipotesis}

Pengujian apakah riset benar atau tidak, dapat ditempuh melalui hasil pengetesan parsial (uji-t) dan simultan. Secara parsial dimaksudkan untuk mengetahui hasil tiap-tiap variabel bebas dan efeknya terhadap variabel terikat yang ditentukan dalam persamaan estimasi regresi berganda. Hasil pengujiannya diperlihatkan pada Tabel 2 di bawah ini:

Tabel 2. Hasil Uji Hipotesis Berdasarkan Uji $-\mathrm{t}$

Sumber : Output program SPSS 21 for Windows (diolah)

\begin{tabular}{|c|c|c|c|c|}
\hline Hipotesis & Pernyataan & $\begin{array}{l}\text { Nilai } \\
\text { t-hitung }\end{array}$ & $\begin{array}{l}\text { Nilai } \\
\text { t-tabel }\end{array}$ & Keterangan \\
\hline $\mathbf{H}_{1}$ & $\begin{array}{llr}\text { Variabel } & \text { seiri berdampak positif } \\
\text { dan } & \text { signifikan } & \text { terhadap } \\
\text { produktifitas karyawan } & \end{array}$ & 2,004 & 1,976 & $\begin{array}{l}\mathrm{H}_{0} \quad \text { ditolak } \\
\mathrm{H}_{\mathrm{a}-1} \text { diterima }\end{array}$ \\
\hline $\mathbf{H}_{2}$ & $\begin{array}{l}\text { Variabel seiton berkontribusi } \\
\text { positif dan signifikan terhadap }\end{array}$ & 2,252 & 1,976 & $\begin{array}{l}\mathrm{H}_{0} \text { ditolak } \\
\mathrm{H}_{\mathrm{a}-2} \text { diterima }\end{array}$ \\
\hline
\end{tabular}




\begin{tabular}{|c|c|c|c|c|}
\hline & produktifitas karyawan & & & \\
\hline $\mathbf{H}_{3}$ & $\begin{array}{l}\text { Variabel seiso memiliki pengaruh } \\
\text { positif dan signifikan terhadap } \\
\text { produktifitas karyawan }\end{array}$ & 2,229 & 1,976 & $\begin{array}{l}\mathrm{H}_{0} \quad \text { ditolak } \\
\mathrm{H}_{\mathrm{a}-3} \text { diterima }\end{array}$ \\
\hline $\mathbf{H}_{4}$ & $\begin{array}{l}\text { Variabel seiketsu berpengaruh } \\
\text { positif dan signifikan terhadap } \\
\text { produktifitas karyawan }\end{array}$ & 4,643 & 1,976 & $\begin{array}{lr}\mathrm{H}_{0} & \text { ditolak } \\
\mathrm{H}_{\mathrm{a}-4} & \text { diterima }\end{array}$ \\
\hline $\mathbf{H}_{5}$ & $\begin{array}{l}\text { Variabel shitsuke berpengaruh } \\
\text { positif dan signifikan terhadap } \\
\text { produktifitas karyawan }\end{array}$ & 5,170 & 1,976 & $\begin{array}{cc}\mathrm{H}_{0} & \text { ditolak } \\
\mathrm{H}_{\mathrm{a}-5} & \text { diterima }\end{array}$ \\
\hline
\end{tabular}

Tabel 3. Hasil Uji Hipotesis

Sumber : Output Program SPSS 21 for Windows

\begin{tabular}{|l|l|r|r|r|}
\multicolumn{5}{c|}{ Model Summary } \\
\hline Model & R & R Square & $\begin{array}{c}\text { Adjusted R } \\
\text { Square }\end{array}$ & $\begin{array}{c}\text { Std. Error of } \\
\text { the Estimate }\end{array}$ \\
\hline 1 &, $691^{\text {a }}$ &, 478 &, 460 & 1,23111 \\
\hline
\end{tabular}

a. Predictors: (Constant), Shitsuke (X5), Seiri (X1), Seiso $(\times 3)$, Seiton (x2), Seiketsu $(\times 4)$

Tabel 3 menggambarkan nilai prosentase adjuster $R$ square sebesar 0,460. Hal ini dapat diterjemahkan bahwa seiri, seiton, seiso, seiketsu dan shitsuke secara bersama-sama dapat menjelaskan produktivitas karyawan sebesar 0,460 (46\%) sedangkan sisanya (54\%) masih tergantung unsur lain.

\section{Interpretasi Hasil}

\section{Pengaruh 5S terhadap Produktivitas Karyawan.}

Hasil kombinasi variabel secara bersama-sama berpengaruh signifikan terhadap produktivitas karyawan dengan nilai 0,000 atau di bawah 0,05. Sedangkan koefisien determinasi (adjusted $R^{2}$ ) sebesar $46 \%$. Harmonisasi kerja dapat terbentuk jika karyawan menyadari arti penting mencari cara agar setiap pekerjaan dikerjaan lebih mudah, hasil yang baik dan menyenangkan (Osada, 2004).

\section{Pengaruh Seiri terhadap Produktivitas Karyawan}

Uji hipotesis $\left(\mathrm{H}_{1}\right)$ memperlihatkan bahwa keluaran SPSS sebesar 0,047 dan di bawah nilai signifikansi 0,05 dengan arah positif. Kenaikan nilai seiri akan diikuti penambahan kinerja karyawan secara signifikan dan sebaliknya. Keputusan sratistik Ha diterima dan Ho ditolak. Pemilahan semua peralatan dan barang antara yang diperlukan atau tidak di area pekerjaan telah menghasilkan efisiensi dalam pemakaian. Dampak lain produktivitas kerja karyawan meningkat. Sejalan dengan hasil penelitian Tanson (2011) bahwa implementasi seiri dan safety dalam $6 S$ di CV. Pandanus Internusa Yogyakarta sudah cukup baik. Ada peningkatan nilai dari 2,9 menjadi 3,0 setelah dilakukan standarisasi pada pilar set in order dan shine.

\section{Pengaruh Seiton terhadap Produktivitas Karyawan}

Output hipotesis $\left(\mathrm{H}_{2}\right)$ menghasilkan hasil pengolahan senilai 0,026 dan lebih rendah dari 0,05 yang bertanda positif. Peningkatan aktivitas seiton searah kenaikan produktivitas karyawan atau statistik menggambarkan penerimaan Ha dan penolakan Ho. Penempatan peralatan sesuai tempatnya sehingga mempermudah pencarian saat dibutuhkan mendesak telah dijalankan oleh 
karyawan di bagian Manufacturing Engineering PT SEIN. Penyimpanan barang di tempat yang telah ditentukan akan memudahkan karyawan dalam mengambil saat kondisi mendadak (Waluyo, 2011). Hasil riset Henriadi (2012) menyebutkan bahwa penggunaan 5S berakibat keadaan fisik lingkungan kerja tampak tertata rapi dan membuat suasana nyaman.

\section{Pengaruh Seiso terhadap Produktivitas Karyawan}

Hipotesis $\left(\mathrm{H}_{3}\right)$ yang telah diuji terbukti bahwa seiso memiliki peranan penting dan positif terhadap produktivitas karyawan karena angka statistik diperoleh 0,027 , nilai yang berada di bawah standar signifikansi 0,05. Berarti Ha diterima namun Ho ditolak. Inspeksi produk dan menjaga kebersihan tempat kerja akan menciptakan suasana kerja lebih nyaman dan mengurangi cacat. Pembuangan sampah, kotoran, benda asing serta pembersihan wilayah sekitarnya akan membantu menciptakan kondisi yang bebas dari cacat dan cela (Waluyo, 2011). Riset yang dihasilkan Apriyatna (2008) mendeskripsikan tentang penciptaan efisiensi kerja, kebersihan lingkungan, produktivitas, kualitas dan keselamatan kerja dapat dibangun dari peraturan, pedoman, kebijakan dan prosedur kerja.

\section{Pengaruh Seiketsu terhadap Produktivitas Karyawan}

Keluaran uji hipotesis $\left(\mathrm{H}_{4}\right)$ menyiratkan kontribusi yang signifikan positif adanya seiketsu terhadap produktivitas karyawan. Angka statistik yang diolah melalui software SPSS didapat 0,000 dan masih jauh di bawah 0,05, indikasinya Ha diterima dan Ho ditolak. Perawatan dan menjaga keberlanjutan seiri, seiton, seiso di lingkungan kerja telah diterapkan di lapangan. Pemeliharaan dan perawatan ringkas, rapi, dan resik harus dikerjakan terus-menerus serta berulang (Waluyo, 2011). Menurut Mintono (2009) dalam penelitiannya bahwa rawat (seiketsu) memperoleh respon $41,1 \%$ dari siswa, sedangkan ringkas (seiri) mendapat apresiasi 29,4\% dan masih dalam kategori sedang saat dilakukan penerapan 5R (5S) di SMK N 2 Wonosari, Gunungkidul.

\section{Pengaruh Shitsuke terhadap Produktivitas Karyawan}

Hipotesis $\left(\mathrm{H}_{5}\right)$ yang diuji menunjukkan dampak shitsuke sangat besar terhadap produktivitas karyawan, jika dibandingkan antara keluaran SPSS senilai 0,00 terhadap signifikansi 0,05. Keputusan yang diperoleh Ha diterima dan Ho ditolak. Pembiasaan dan pelatihan untuk membuat kondisi lapangan selalu baik telah dilakukan oleh sebagian besar karyawan meskipun awalnya berat dalam memulainya. Pendapat Waluyo (2011), rajin atau pembiasaan dapat terjadi karena pelatihan maupun peningkatan kemampuan terhadap tugas meskipun sulit dilakukan. Sesuai hasil riset Kartika (2011), faktor $5 S$ yang dijalankan dengan baik sangat menentukan efektivitas kerja di departemen produksi.

\section{KESIMPULAN DAN SARAN}

Secara simultan $5 S$ mempengaruhi kinerja produksinya dengan proporsi sebesar $46 \%$ sedangkan sisanya $54 \%$ ditentukan faktor lain. Dibutuhkan hubungan kerja yang harmonis, mengetahui tingkat kepentingan dalam mengerjakan segala tugasnya secara lebih terstruktur. Implementasi budaya $5 S$ di divisi Manufacturing Engineering Departement PT Samsung Electronis Indonesia Cikarang-Bekasi terbukti dijalankan dengan baik oleh karyawan. Pengerjaan pemilahan (seiri) dengan meletakkan dan menyimpan sesuai tempatnya akan mempermudah jangkauan sehingga lebih efisien dalam pemakaiannya. Barang-barang yang mengurangi ketidakefektifan dalam bekerja dapat diletakkan di tempat yang jauh atau dibuang.

Penataan (seiton)merupakan kegiatan penyimpanan secara tepat terhadap benda-benda maupun peletakan secara benar agar saat kondisi darurat atau mendesak akan lebih mudah dalam pencarian. Akibat lebih jauh adalah lingkungan kerja lebih rapi dan nyaman. Seiso secara 
statistik mempunyai efek yang signifikan dengan arah positif. Pembersihan (seiso) melalui pembuangan sampah, kotoran dan benda asing yang tidak perlu sebaiknya dibuang dan dijadikan sebagai budaya kerja. Tempat kerja yang dipakai dalam aktivitas sehari-hari harus terhindar dari cacat dan cela. Hal ini akan menumbuhkan hasil kerja yang efisien, lingkungan kerja yang bersih, produktivitas, pekerjaan yang berkualitas serta keselamatan kerja. Perawatan atau pemantapan (seiketsu) secara berkesinambungan dan melakukan pengulangan akan menjaga tingkat keringkasan, kerapikan serta keresikan baik mencakup kebersihan individu dan sekitar lingkungan. Kondisi ini akan menambah gairah karyawan untuk meningkatkan produktivitasnya. Kerajinan dan pembiasaan (shitsuke) seperti pelatihan dan peningkatan kemampuan untuk bertindak terhadap apa yang diinginkan meskipun terkadang cukup sulit. Apabila semua karyawan bergerak bersama-sama maka menjadi modal dalam menciptakan efektivitas kerja di departemen produksi.

\section{Ucapan Terima Kasih}

Peneliti mengucapkan terimakasih kepada PT SAMSUNG ELECTRONICS INDONESIA, Cikarang, Bekasi dan Universitas Presiden yang menyediakan fasilitas dan dorongan untuk melakukan penelitian serta mengucapkan terima kasih kepada Universitas Tarumanegara Jakarta yang telah mempublikasikan paper ini ke dalam Jurnal Muara Ilmu Ekonomi dan Bisnis.

\section{REFERENSI}

Apriyatna, Y (2008), “Analisa Penerapan 5R (Ringkas, Rapi, Resik, Rawat, Rajin) di Bagian Divisi Sipil Umum II (DSU II) PT. Wijaya Karya (PERSERO) Tbk. Pada Proyek PLTU (Pembangkit listrik tenaga uap) Indramayu, Resipository Universitas Widyatama, http://localhost:8080/xmlui/handle/123456789/1004

Creswell, J. W. 2014. Research Design: Qualitative, Quantitative and Mixed Methods Approaches, 4 Edition. London: Sage

Halim, Lorena (2006), "Perancangan 5S Bagian Produksi dan Bagian maintenance: PT Harapan Widyatama Pertiwi (Unilon)”. Skripsi. Jakarta: Universitas Bina Nusantara.

Hayu Kartika (2011), “Analisa Pengaruh Sikap Kerja 5S dan Faktor Penghambat Penerapan 5S terhadap Efektivitas Kerja Departemen Produksi di Perusahaan Sepatu, UMB-Jakarta

Henriadi (2012), "Perancangan Fasilitas Pabrik Tahu untuk Meminimalisasi Material Handling", Jurnal Teknik Industri, Vol 13, No 2 (2012)

Kartika, H dan Hastuti, T (2011), "Analisa Pengaruh Sikap Kerja 5S dan FaktorPenghambat Penerapan 5S Terhadap Efektivitas kerja Departemen Produksi di Perusahaan Sepatu". Jurnal PASTI Volume V. Jakarta: http:Fteknikindustri.mercubuana.ac.id 2011.

Mintono, A (2009), "Penerapan Metode Ringkas, Rapi, Resik, Rawat, dan Rajin (5R) di SMK N 2 Wonosari Gunungkidul”. Skripsi. Yogyakarta: FT UNY.

Nina A, Purnomo (2013), Implementasi 5s Pada CV.Valasindo Menggunakan Pendekatan Ergonomi Partisipatori Jurusan Teknik Industri Universitas Islam Indonesia.

Osada, T (2004), "Sikap Kerja 5S: Seiri Pemilahan, Seiton Penataan, Seiso Pembersihan, Seiketsu Pemantapan, Shitsuke Pembiasaan". Penerjemah: Dra. Mariani Gandamihardja. Jakarta. Penerbit PPM.

Sugiyono (2015), Metode Penelitian Pendidikan (Pendekatan Kuantitatif, Kualitatif Dan R\&D), Alfabert, Bandung.

Tanson (2011), "Implementasi 6S di CV. Pandanus Internusa Yogyakarta". Universitas Atma Jaya Yogyakarta, 2011

Waluyo, Prihadi (2011),"Analisis Penerapan Program K3/5r Di Pt X Dengan Pendekatan Standar Ohsas 18001 Dan Statistik Tes U Mann-Whitney Serta Pengaruhnya Pada Produktivitas 
Karyawan”. Jurnal Standardisasi ,Vol. 13, No.3. Jakarta: Pusat Audit Teknologi Badan Pengkajian dan Penerapan Teknologi. [Online] Available. 2011 (Diakses 29 Mei 2012). 